\title{
DOCUMENTING THE CULTURAL HERITAGE ROUTES. THE CREATION OF INFORMATIVE MODELS OF HISTORICAL RUSSIAN CHURCHES ON UPPER KAMA REGION
}

\author{
S. Parrinello ${ }^{1}$, F. Picchio ${ }^{1}$, R. De Marco ${ }^{1}$, A. Dell’Amico ${ }^{1 *}$ \\ ${ }^{1}$ DICAr, Dept. of Civil Engineering and Architecture, University of Pavia, Pavia, Italy - sandro.parrinello@unipv.it, \\ francesca.picchio@unipv.it, raffaella.demarco@unipv.it, anna.dellamico@gmail.com
}

\author{
Commission II, WG II/8
}

KEY WORDS: H2020 RISE, Cultural Heritage Routes, Digital Documentation, Information Models Library, Laser scanner survey, aerial photogrammetry, Upper Kama Region.

\begin{abstract}
:
The present paper illustrates the documentation activities developed since 2013 on Upper Kama territories, preliminary to an extensive and joint research action within the European project "PROMETHEUS" (2019-2021), which aims to produce digitized databases and models for the management of the main religious monuments present on this Russian area, nowadays endangered by risk of conservation. The project is funded by the EU program Horizon 2020 - R\&I - RISE - Research \& Innovation Staff Exchange Marie Skłodowska-Curie, and it is aimed at the definition of inter-sectoral collaboration protocols for the development and promotion of a new methodology for the development of reliable 3D databases and models of monumental complexes in Upper Kama region. The project, that involves the collaboration between three Universities (University of Pavia, Italy, Polytechnic University of Valencia, Spain, Perm National Research Polytechnic University, Russia) and two enterprises (EBIME, Spain, SISMA, Italy), aims to promote actions to develop interdisciplinary activities for the documentation, management and production of collaborative H-BIM models, for the start-up of monitoring and development activities on this specific Cultural Heritage. Researches and initiatives conducted in the previous years on Upper Kama territory highlight potentialities and opportunities of digital survey to define a basis of knowledge that is both scientific and technical, for future interventions on endangered architectural heritage, where academies, companies and administrations promote actions to develop interdisciplinary documentation activities through collaborative management H-BIM models and an intervention protocol on Cultural Heritage.
\end{abstract}

\section{INTRODUCTION}

The fires and invasions of all preceding epochs were no more destructive for our monuments of antiquity than the indifference to our native past that reigned during the past two centuries.

(Boris von Eding, 1913)

Analysing the documentative production, in a specific historical period and in a specific territory, concerning its historical architectural heritage, it is possible to understand the sociocultural attitudes related to its conservation and promotion. Such behavioural attitudes, both of a single individual or a society, have conditioned not only the image and the identity of the architectural system and of the landscape that hosts it, but they also have determined practices and activities that condition the mechanisms of protection of the heritage (Jokilehto, 1998).

This analysis has to be developed in the aim of working with methodologies and cognitive practices experimented on a specific context, in territories where, instead, these procedures are not consolidated. Regarding the aspects of documentation for the restoration and preservation of historical architecture, the consolidated experiences in the Mediterranean and European context are raising and increasing an international awareness that focuses on the importance, even economic, of this safeguarding of historical identity and of the connected image of the entire landscape and cultural systems. The attention that these safeguard methodologies for heritage are receiving within the most recent EU programs has initiated, in recent years, an awareness-raising process extended to the recognition of heritage for its protection (Feilden, Jokilehto, 1998), supported and expanded in a phenomenon of public and territorial involvement (Byrne, 2008) that configures as a worldwide example (Logan, 2001). However, the goal of standardizing awareness programs highlights a difficulty in the uniformity of methods and languages (Langfield et al., 2010). The variety of characters of Cultural Heritage (Logan, 2012), in particular the Built Heritage, denies the provision of a "static" method of knowledge, where absolute and invariable parameters applied to each context should instead be oriented towards a "dynamic" documentation and intervention protocols (Kioussi et al., 2013). Therefore, the indexing of archives, and the possibility of interconnecting metadata and databases among them, moves the general orientation of these systems towards a structuring of the same archives and of systematized data through methodological phases and products (drawings, models and more elaborated out-puts of critic synthesis and interpretation). Through the infinite variety of such products and interpretations, systems must be placed in order to support and interpret the reading of these both technical-operational and cultural specificities, from whose analyses they derive

\footnotetext{
* Corresponding author
} 

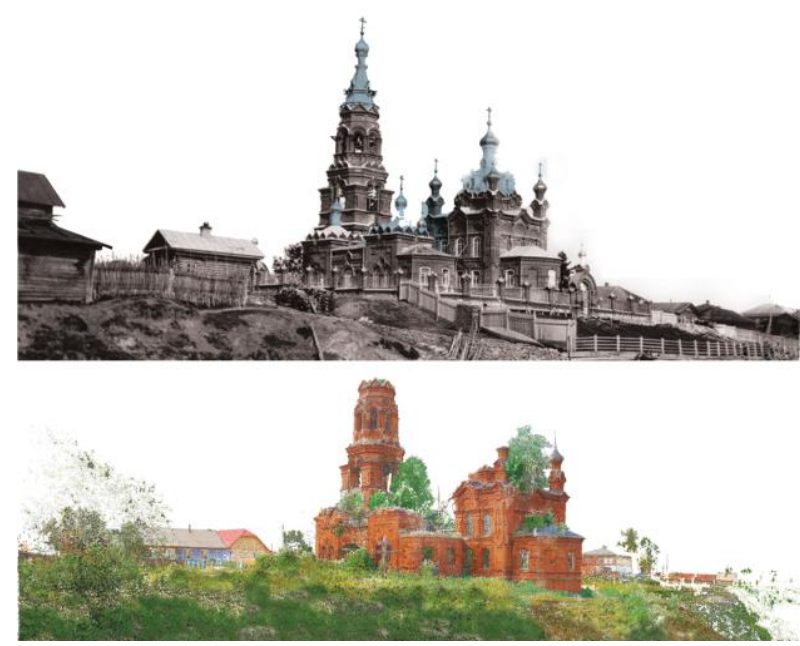

Figure 1. The Church of the Annunciation in Pokcha: a comparison between an historical photo and the point cloud from the survey of 2018 summer school.

intervention and implementation practices that can relate the past, the present and the future, about the life of a specific cultural system or an architectural element that refers to it. The goal is to systemize a proposal for an internationally shared method, from which to develop a management program for Cultural Heritage, capable of adapting ad hoc to different contexts and scales from the monument to the territory, particularly in regions where heritage awareness has only recently become a socio-cultural topic in development (Kioussi et al., 2011). The definitions and regulations promoted by the European committees, in the classification of material and immaterial values of the heritage on indexes and parameters of evaluation, now surpass today's international geo-political boundaries, recognizing common forms and characteristics that bring together people and traditions around original cultural areas, today administratively secondary but still influential in contemporary communities.
The case of the European geographical basin is witnessing a secular cultural extension towards close continents, in particular the Asian one, and, at the same time, it performs a resilience in maintaining the architectural features of Western culture in exemplary contexts. The "European Russia", whose architectural values are strongly permeated by West models, represents an exemplary case of this phenomenon.

In these border territories, as those places where imported cultural events take place and which have acquired their own identity, characterization and specificity over time, it is the path of these cultural models to define a greater enrichment of identity, even more than the monument itself.

This richness is therefore expressed into "Cultural Heritage Routes" which, understood and qualified, can describe terms of cultural connections that are set on basins of intercontinental extensions.

Models like those of the Orthodox churches come from the Middle East into the Mediterranean basin, and they cross Europe vertically from Greece to reach the Urals, where they meet with other models that from the Middle Eastern basin have climbed the great rivers such as the Volga or with models that have crossed the Gobi steppes.

In these border places, Cultural Routes determine, even in a material way, the presence of monuments in the area. The river is in the Russian taiga the way to cross and penetrate the territory acquiring its values. It is with the river that cultures and models of civilization are transported. Today, in these territories, an administrative landscape, in the absence of conscious activities aimed at preserving built heritage, has led to phenomena of neglect and abandonment and to the loss of a wide Cultural Heritage. This aspect is partly due to the devastating assault policies that the Soviet regime has applied to historical monuments over the past century (Abeti, 2018). In this way, this aspect contributes to express the difficult survival of a collective material memory, that is instead central expression of flows of communities and cultures across Europe. Since 2013, DAda-LAB Laboratory of University of Pavia has developed multiple research guidelines on the enhancement and conservation of Cultural Heritage in the border territories of European Russia, within cognitive actions of analysis and
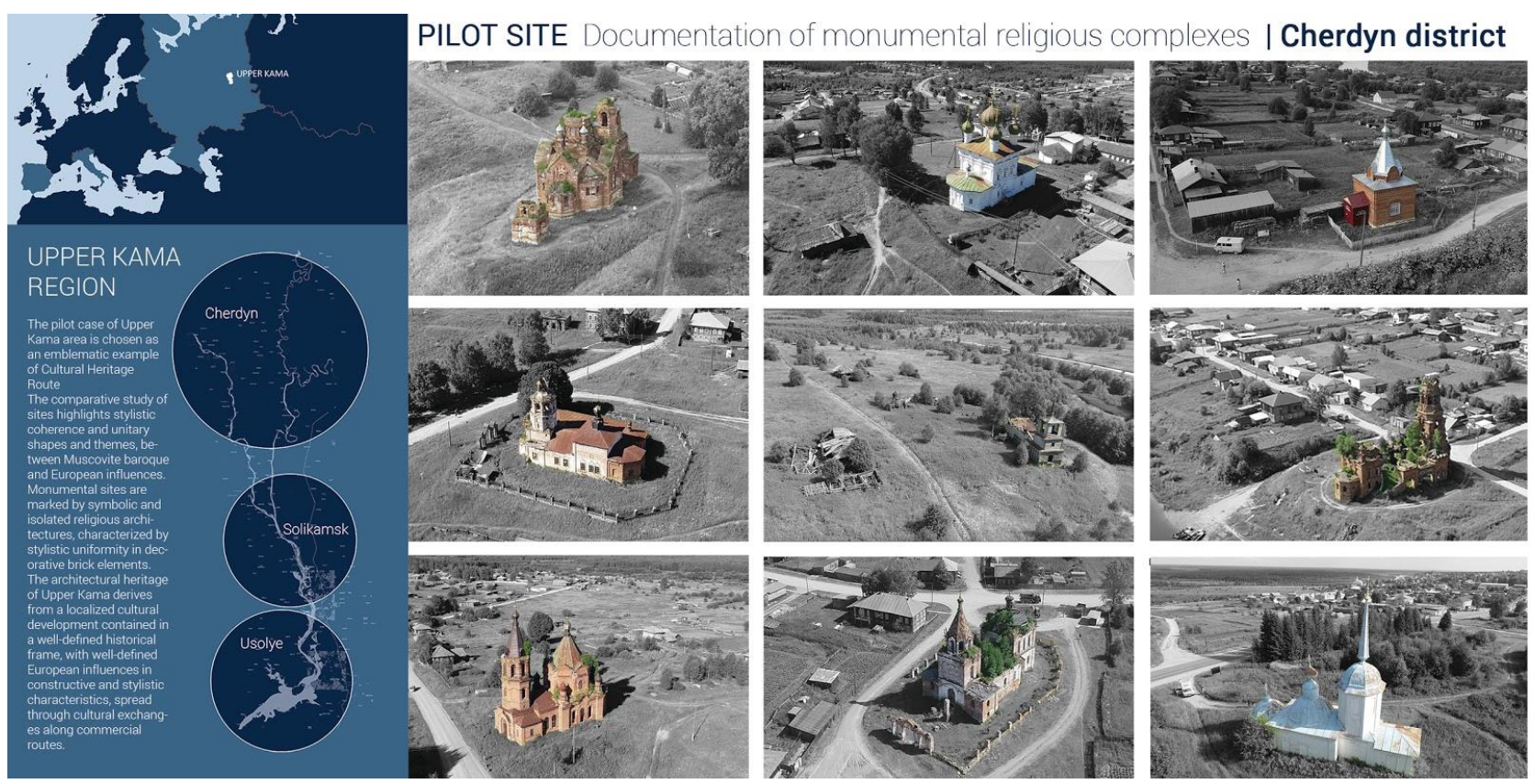

Figure 2. The territory of Upper Kama and its districts (Cherdyn, Usolye, Solikamsk). Some examples of types of churches and monumental sites found in the Cherdyn district. 
digital documentation of monumental churches and traditional wooden settlements. Within the collaboration with Perm National Research Polytechnic University, the research activities conducted in Upper Kama have established a double channel of sharing and scientific comparison between Italy and Russia, focused on the investigation of the monumental architectural sites distributed along Kama and Kolva. The widespread nature of this heritage, at the center of the itineraries organized during Summer School experiences (2015-2018) and with the participation of researchers and students from different universities and international institutes, has provided for the application of digitalization and architectural survey methods that have highlighted the importance of drawing and graphic product in the description and census of monumental units and of the surrounding landscape. In the same way, it has been highlighted how the critical drawing, both $2 \mathrm{D}$ and $3 \mathrm{D}$, defines not only a documentative contribution but a starting cognitive support, on which to dispose and integrate necessary multidisciplinary contents that can range on the entirety of Cultural Heritage knowledge, also in a technological, planning and administrative nature.

These considerations have encouraged, both methodologically and contextually, the structuring of a broader project idea, aimed at defining inter-sectoral collaboration protocols for the development and promotion of reliable 3D Information Models Libraries on architectural heritage. The objective, starting from the experimentation of Upper Kama, is to establish a dynamic methodological protocol that can be replicated in Europe, developing an active but standardized approach to the "digitized planning" of Cultural Heritage Routes.

\section{UPPER KAMA TERRITORY AND HERITAGE}

The territory of Upper Kama is witnessed of the specific historical-political actions and of their effects on the built heritage. The monumental historical architectures, both religious and civil, coexist in the territory in a widespread way, distributed along the Kama river valley and endangered by different critical issues, both anthropogenic and natural. This phenomenon collects a heterogeneity of architectural elements, with stylistic and constructive varieties, and a multiplicity of building materials and related pathologies of decay and conservation, defining an unique panorama for its specific conformation and, at the same time, an international recognition of the widespread cultural problem.

The Upper Kama region is located north of Perm Krai, with a territorial extension of about $7.000 \mathrm{kmq}$, limited to the west by the chain of Ural Mountains, and to the north by the Komi region. The territorial richness is defined by the presence of mineral resources that have given the region the role of commercial crossroad throughout the Imperial period, realizing during the $15^{\text {th }}$ century a cultural and architectural development promoted by merchant families, such as Stroganov or Golitsyns. The initiatives of the merchant class have contributed to the development of complex urban settlements, including in addition to the industrial center also residential buildings and Orthodox complexes, churches, bell towers and family chapels (Brumfield, 2008). The salt trade, from Europe beyond Urals to China, has increased trade flows and intermediate settlements along this route, centred around the main districts of Solikamsk (1430), Cherdyn (1535) and Usolye (1606) (Parrinello, Cioli, 2018).

The $19^{\text {th }}$ century, after the revolution of 1917 , was marked by a strong political split, and the new industrial configuration has influenced the territory and the Russian society and it has also profoundly modified the distinction between rural and urban

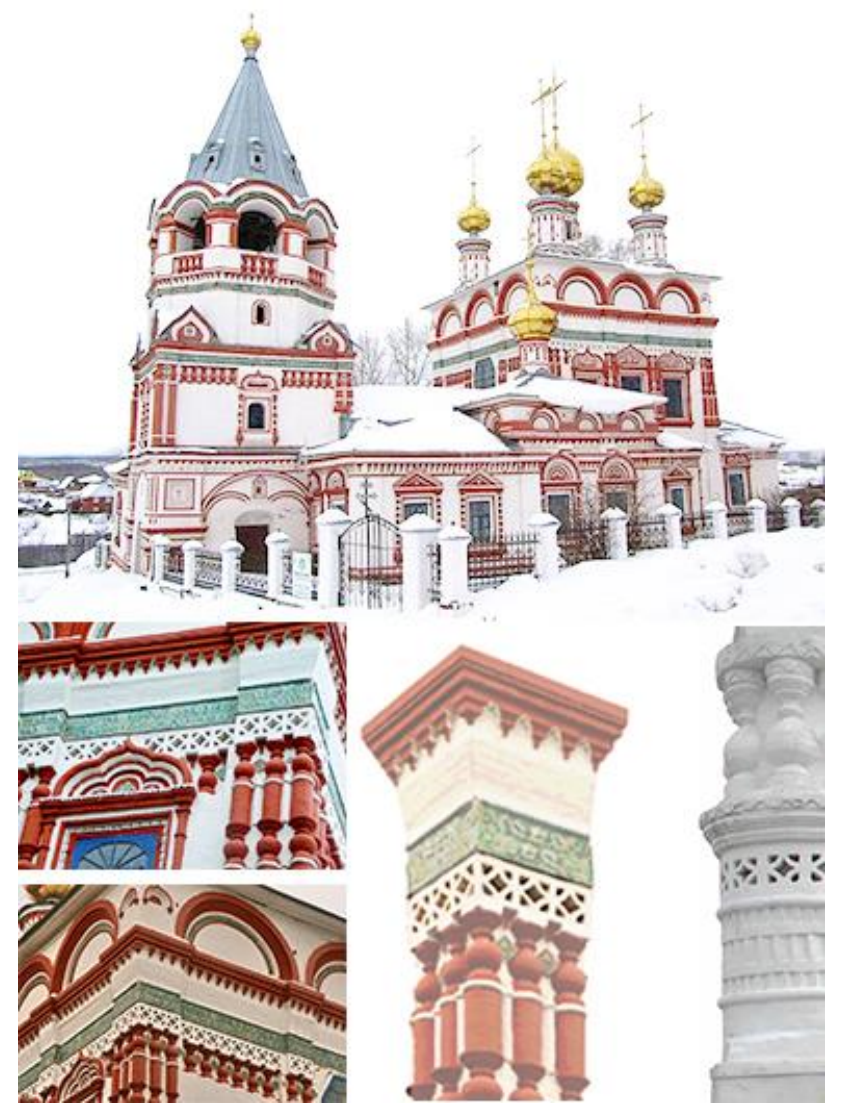

Figure 3. The Tserkov church (Solikamsk) an example of the use of the "zjuchkoviy" (Ж - Жучковый орнамент).

environment, marking a change in the approach to the building and its image in the landscape. A new social structure that redesigns the structure of territory, influencing the redistribution of properties and the conservative management of connected monuments. In this way, most of the historical architectural complexes of the Kama valley have seen their transformation into ruins, today as survivors of a past era but in a difficult way of intervention and insertion in the territorial context, in a constant decline under the weight of snow and of the atmospheric agents on their ruins (Brumfield, 1995).

Upper Kama region is still today composed of more than 50 monumental sites, spread over the territory but interconnected by a single cultural language, distinguishable as an historicalmateric link, but where management planning aimed at protecting these assets is absent. The attention still reserved by the local population to the image of these historic monumental landscapes is difficultly matches restoration and management initiatives by administrations, contrasted by the critical nature of conservative intervention and by the lack of adequate bases of metrical and architectural documentation of Orthodox churches. Through the comparative study of sites, the stylistic coherence in unitary forms and themes is evident, as expression of an actual historical-stylistic identity. Looking to the main sites, it is possible to find a colonial influence, whose forms find order in the importation of the European style (first Baroque and then Neoclassical) influenced by the local cultural models of vernacular style. Thus, architectural reference models, first applied in urban contexts within the "palace" model, are moved inside villages, influencing the construction of buildings with monumental forms and rich geometries as expression of the political and economic development of these settlements. 
Each district can be identified by a nucleus with a religious structure that becomes a symbol and orientation point around the monumental building. The church identifies the village, in a correspondence of sign-society where the monument itself is the fulcrum of cultural aggregation and it becomes a symbol of community, village, home (Mumford, 1963).

The large brick volumes dominate the entire village, with their different proportions compared to the small wooden doma that rise along the streets, and the Orthodox tradition contributes to define architectural canons translated into typological characters of unification of the image of churches: the cross nave system with two main aisles, with a cuboid development culminating in the semi-cylindrical apse; the central module turned into pillars; the complex coverage schemes, enriched by subsidiary domes.

The external surfaces are drawn according to rigid geometric patterns, through an alternation of full and empty spaces that not always corresponds to the layout of the internal structure of the church. The facades are intended as scenes that dialogue with the landscape while the interiors are reduced to protect from the cold (Brumfield, 1993). The same building materials direct the identity of the place, such as settlement nucleus built on river clayey soil: the brick becomes the privileged material, alongside the traditional wooden architecture for civil constructions. The application of geometric decorations in brick is found in the traditional "zjuchkoviy" motifs, projected on the external surfaces of churches.

\section{MANAGEMENT AND INTERVENTION PROTOCOL FOR UPPER KAMA CULTURAL HERITAGE}

Moving from the cities of Usolye and Solikamsk, configured as emerging urban centers of the area and better preserved in their historical and architectural heritage, the traditional landscape of villages, located between the forest and the river, shows a settlement dispersion in the territory that is at the same time cause and effect of the lack of local monitoring and management practices. From the hills of Pyskor, to the district of Cherdyn, towards the northern sites of Bondjug, Kamgort, Iskor and Nyrob, the presence of an implicit cultural route connects the architectural dialogue between churches and monuments along the Kama. Churches, visible in the elevation of their domes and bell towers, define a cultural path of value and immersion in the disappearing historical heritage.

Thus, the documentation of the image of place and its monuments, framed in their current condition, becomes an objective of territorial monitoring of the evolutionary processes that involves culture and local identities, and it defines a path of initiative and evolution for the development of adequate maintenance and management plans.

The complexity of relationships that qualifies the structure of the identity of place, consisting of the monument and its relationship with the landscape of Kama, attempts to be transposed into a new "virtual" conformation. In this way, the act of digitization becomes a methodological input associated to a deeper cognitive process, with the decomposition and critical reconstruction of the architectural unity through a semantic classification of its sub-components. The objective is to consolidate an architectural, digital and three-dimensional model, as a result of content and form on the current and future status of the monument.

The research intends to develop a documentation protocol for Upper Kama through the definition of an archive of libraries of architectural models surveyed in the territory, for the digitization, archiving and management of monumental complexes, with the possibility of developing reuse and interaction processes of data through collaborative management and implementation processes. The research and documentation of historical constructive units unifies the languages of architectural representation, pursuing methodological procedures of coding and processing for geometric and parametric virtual models of complexes, based on principles of transparency, communicability and repeatability of methods and results by researchers to users, both administrative-operational and public-fruitive.

Starting from the previous research lines developed over years, the aim of the European project PROMETHEUS is to implement an interdisciplinary action for the documentation and structuring of information on architectural heritage, promoting the training of researchers on the constructive and historical value of Cultural Heritage Routes. The definition of a "Charta", for the repeatability of the action, will be pursued with a practical action on the monuments present along Upper Kama

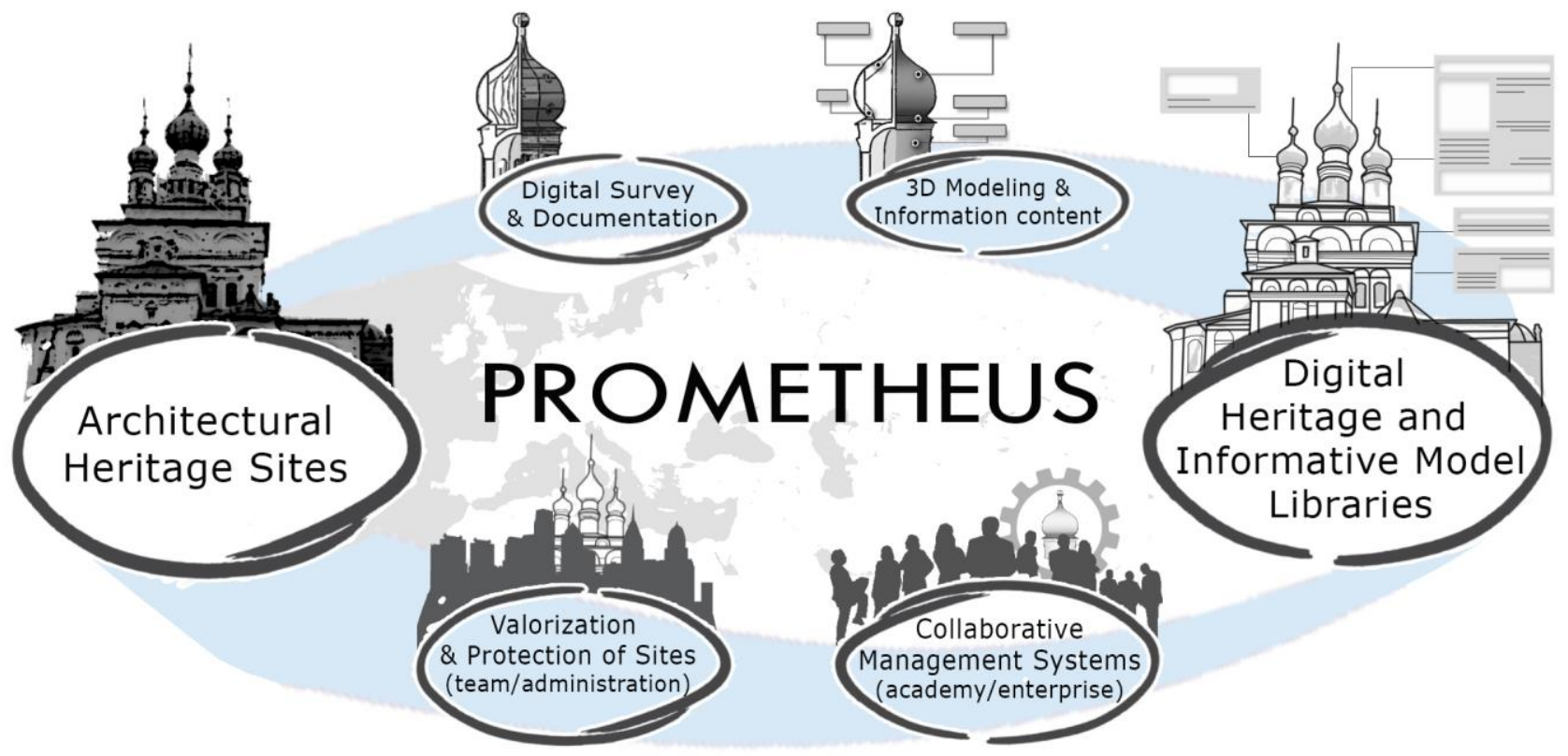

Figure 4. Methodological and action framework of H2020 RISE project PROMETHEUS. 


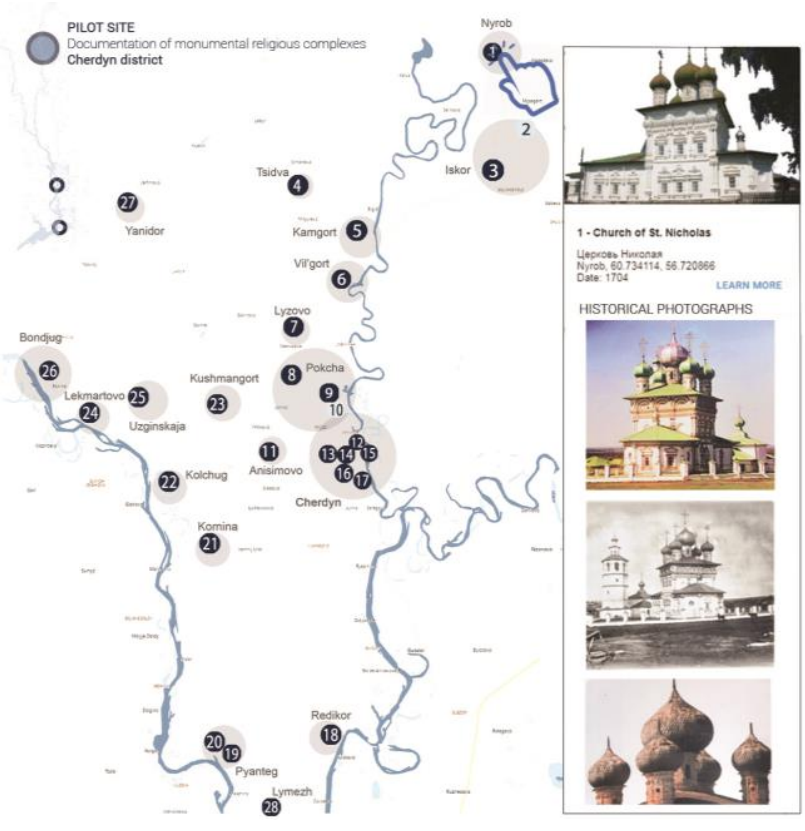

Figure 5. One of the aims of PROMETHEUS project is the creation of interactive maps to which information about religious monumental complexes can be associated.

route (Russia) as pilot study case, aware of the methodological and operational dynamism necessary for the extension in the repertoire of European routes.

The network of scientific sectors involved in the action, ranging from the technological field to the practice of territorial planning, favours the cultural and thematic enlargement necessary to develop the skills required by administrations and management committees. The competences in the digital survey of architectural heritage, at the base of the starting process for Information Models Libraries, recall the development of integrated databases on architectural heritage survey, that inevitably pass through the requirement of certification and structuring of the acquired data, in terms of both reliabilities to the "real" configuration of conservation and architectural status and in terms of completeness and management of documentation data. In particular, the metric component is confirmed as primary information, even if not exhaustive, required to start the architectural analysis approach. It is applied to define the documentary base to which the complete database of data refers, upgraded of materic, historical and landscape features, necessary for the global understanding of the built site, in terms of architectural components and their diagnosis.

The optimization of these databases and material-morphological models is followed by the implementation of knowledge on construction technologies and census archives related to architecture, together with historical and territorial planning practices. This is followed by a "scaled" modelling procedure, where the predisposition of Architectural Building Families, as classes of hierarchical components from the survey of churches and implemented with information contents, allows to proceed with a semantic drawing of the built heritage through a modelling strategy by over-classes. This procedure starts with the definition of Typological Constructive Modules that compose the structural system, to then compose the architectural complex and the surrounding landscape through a parameterization of geometric components that, at different levels of detail and of iconographic synthesis, identify flows and values of services, connections, sites and territory.
From the architectural knowledge, it derives a comparison with the operational practice, allowing a dialogue with the professional companies that operate in the project intervention of restoration and management of BIM systems and methodologies to develop procedures and actions for the implementation of databases and academic models. Precisely in the flows of technological, historical and formal correspondence, the territorial model responds to administrative and managerial requests, offering the information content to an interactive reading for multiple in-depth channels, and allowing the architectural shape to change its digital expression depending on the degree of requested information. The Collaborative Model, once structured, configures a new form of shared database, where the search result becomes the starting point for the life of the building after the survey project, during restoration and maintenance, powering the implementation of a new use of heritage.
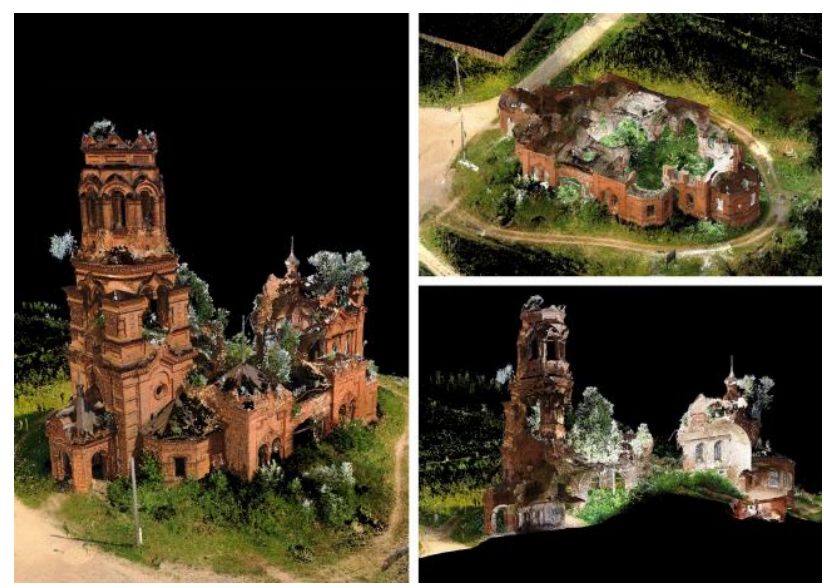

CHURCH OF ANNUNCIATION

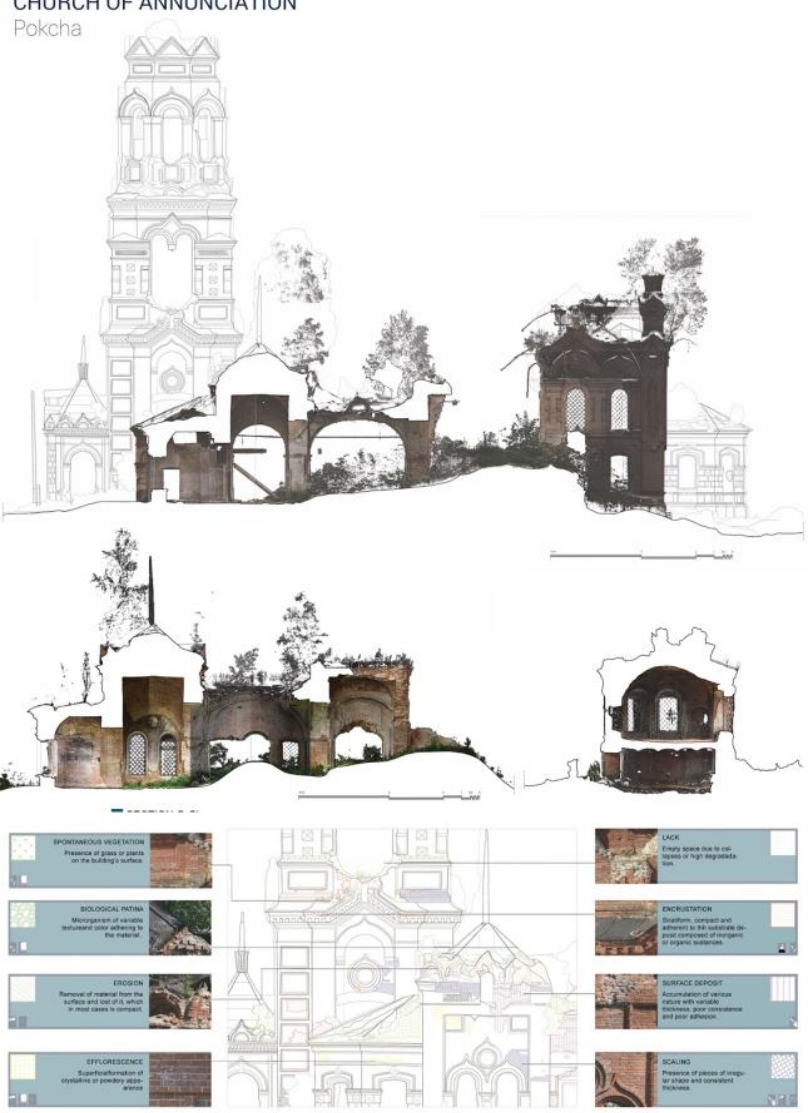

Figure 6. Point cloud views and drawings with analysis of the decay of the Church of Annunciation. 


\section{FROM THE 3D DATABASE TO THE TERRITORIAL MODEL: STRATEGIES OF DEVELOPMENT AND CONSTRUCTION}

The research and experimentation activities conducted since 2015 have allowed to test and optimize the digital documentation procedures towards the standardization of a survey method for Upper Kama, proportioned and evaluated on the specific realities of architectural complexes, preserved, abandoned or ruins. Compared to the experiences of 2015 and 2016, the campaign conducted in 2018 has expressed a greater awareness and commitment in the evaluation of correspondence processes between survey databases and information modelling systems, designed on the territorial scale.

The research has concerned the strategy of testing integrated digital survey methods, both terrestrial and aerial (Parrinello, Picchio, 2014), aimed at defining methodological protocols for the development of reliable 3D models and new operational programs. In these terms, the adoption of a metric surveying methodology implemented with Terrestrial Laser Scanner (TLS) instrumentation presents itself as a strategy capable of providing an adequate dimensional basis for the structuring and certification of the metric database and of the supplementary photographic, critical and census data, acquirable on architectural and territorial components. The strategy of integration of Lidar and photographic instrumentation, of terrestrial type with static application (Terrestrial Laser Scanner, Camera Reflex for close-range photogrammetry) and dynamic acquisition (Mobile Stencil, Ricoh Camera) and of aerial type (DJI drones for SfM photogrammetry and for photographic investigation), is applied ensuring a total coverage of the context and it is conducted at multiple levels of observation and stratification of the built system, territorial, architectural and constructive (Parrinello, Dell'Amico, 2018). The laser scanner acquisition has defined the reliable geometry of building complexes, adopting a photogrammetric drone Structure from Motion reconstruction for roofs and upper portions of facades, till to reach the surveying of landscape. Photographic census is also considered in the objectives of implementation for the knowledge of sites, with 2D panorama and spherical products able to complete the geometric data with materic and multimedia contents.

The results of this methodological structure conduct to a library of global georeferenced Digital Databases, as sparse models, fully conceived as colorimetric models of monuments and their landscape context, metrically reliable and highly descriptive, to implement information contents through the correspondence between points or mesh surfaces and graphic-informative elaborations.

The methodological choice is made with the awareness of fastoperability and adaptability required to digital survey, to decline to the many spatial and morphological configurations of the wide historical-architectural catalogue of Upper Kama sites. Particularly, their complexity is due to the stylistic variety (from Baroque Stroganov to the Twentieth Century restorations) and architectural distribution, found within blocks, environments and apparatuses belonging to the built complexes diffused on territory. Therefore, survey operations provide a primary structure of data integration processes, comparing real objects and virtual models for the implementation of analysis.

More advanced digital models can produce a global architectural digitizing action, framing objects in spatial modules, structuring the analyzed features and transforming the output of instruments into optimized 3D databases, responding to dynamic and standard requirements of European regulations.

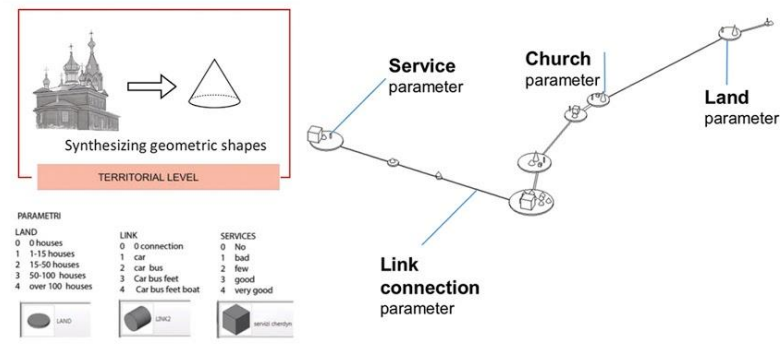

Church Parameter

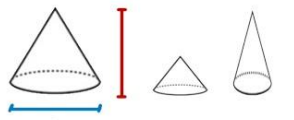

The geometric shape changes by inserting the two -Height parameters matched to a value chosen from a scale of values defined to indicate the importance of the church. -Diameter that indicates the conservative state in which you
reverence the church.

Link connection Parameter

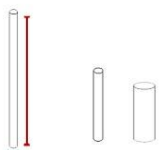

The geometric shape changes by inserting the two parameter Length that indicate the distance between the two center.
Diameter that change which changes according to the number of transport services available to reach the center

Land Parameter

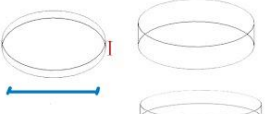

The geometric shape changes by inserting the two parameters : - Height that indicate the number of inhabitants. - Diameter that change which changes according to teritoria
extension $\left(\mathrm{KM}^{2}\right)$.

Service Parameter

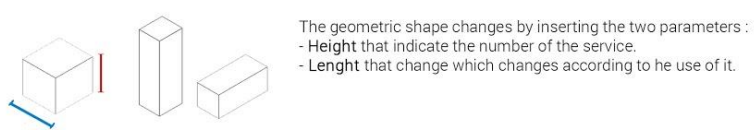

Figure 7. First considerations made on the construction of a simplified informative model of the territory. The simplified three-dimensional geometric forms define and describe the characteristics of the territory through the insertion of specific parameters. Each simplified model of church is expected to connect a more detailed model that describes the different technological elements in detail.

Data collected on site, through the different instruments, explain a superabundance of information that, if not elaborated and discharged, loses its communicative function. The set of data and information, as to become a communication tool for different users, must find the right means of explanation. Drawings, symbols, geometries, images, sounds and multimedia elements have their own peculiarities and equal informational dignity if justified by a specific purpose.

The normalization of integrated informative/cognitive models requires a multidisciplinary approach, which considers the peculiarities and requirements of potential users. In fact, the creation of digital Information Models, structured on the geometric representation of architecture, can connect more information, derived from diagnostic tests and analysis of the materials coming from different supports. Therefore, Information Models can create a single organic system of management and sharing for implementation.

Order, completeness and implementation of data define the basis of BIM methodology. The models can be defined at different detail scales according to the descriptive requirements (Pavan et al., 2017). From a territorial synthesis model, as descriptor of the parameters that characterize territory (services, means of transport, activities, monuments) to a detailed model describing the decorative and technological parameters aimed at the conservation and management of the same monument. 
The elaboration of models that describe and manage territory into collaborative platforms, as offered by BIM platforms, can allow different categories of operators to work and manage data in different contexts, monitoring and planning specific actions or widespread interventions (Osello, Ugliotti, 2017). This service represents an opportunity to develop the methodological protocol and its application on Built Heritage, even after the project, keeping researchers connected and operative to extend the requirements of knowledge, control, management and site planning.

\section{CONCLUSIONS}

Cultural Heritage Routes, although diversified by type, territory of location and by the involving urbanization processes, have common architectural and landscape features if they refer to classification processes. The semantic levels in which these characters can be decomposed are able to define typological "libraries" of architectural and construction components, developed with analysis languages and coding common systems to the global community. The identification and definition of their characteristics is a fundamental action for the digitization of these cultural contexts, as both historical and natural landscapes, architectural monuments and archaeological sites. Within the process of codification and digitization by elements, the proposal of unified documentation protocols and digital information models on a variety of diversified cultural contexts is realized, promoting a territorial digitization action from the architectural system to the territorial one.

The collaborative action that PROMETHEUS attempts to promote is the synergy between academic partners and companies that, having already worked independently on typologically and geographically similar contexts, have acquired the experience necessary to start the operational processes set by the project, and that for the first time collaborate to share a joint and methodologically repeatable process. Documentation and management protocols, no longer fragmented but extended to entire cultural areas, will allow to validate the collaboration between partners, the obtained outputs and to optimize the method according to context, new technologies and an update of the relative application to cultural routes. In this way, the results of PROMETHEUS will support the recognition and establishment of "protected" areas, architectural and landscape complexes within these routes, contributing to the development and progress of architectural and cultural conservation within the European and worldwide heritage.

The project, which attempts to create a dialogue on heritage using the common language of "drawing", assumes collaborative platforms and interdisciplinarity between the partners to provide digital archives, able to contain information about landscape and architecture as containers for the aspects that have characterized Upper Kama landscape, which in its signs stratifies and sediments the traces of history.

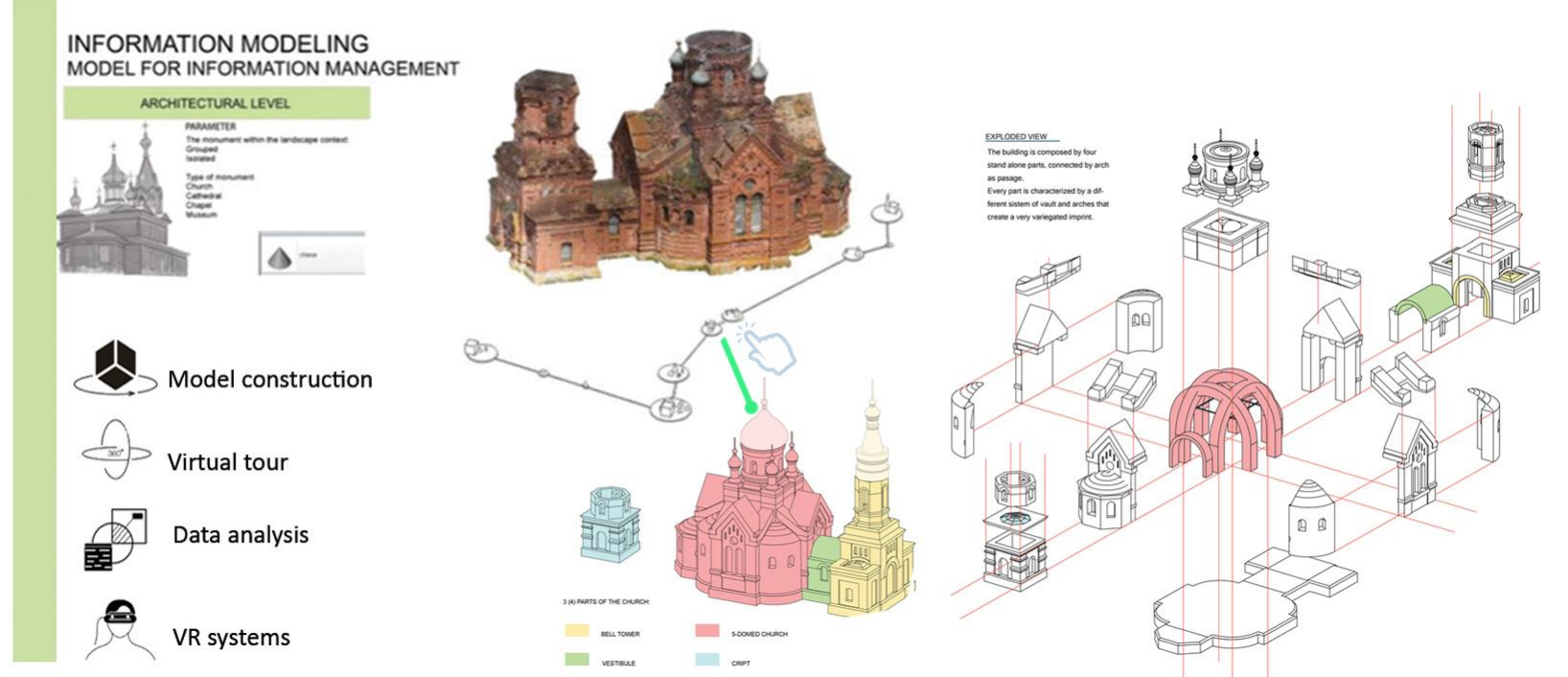

Figure 8. Complexity of parameters and links between information system and architectural complexity. The different levels of graphic interaction and implementation conduct to deeper levels of knowledge and morphological detail of churches. 
Marie Skłodowska-Curie grant agreement No 821870.

The editorial responsibility of the paragraphs is recognized to:

S. Parrinello for paragraphs 1 and 5, F. Picchio for paragraph 2,

R. De Marco for paragraph 3, A. Dell'Amico for paragraph 4.

\section{REFERENCES}

Abeti, M., 2018. Architettura della libertà. Avanguardie e rivoluzione bolscevica. Delta 3 edizioni, Avellino.

Brumfield W.C., 1993. A history of Russian architecture. Cambridge University press, Cambridge.

Brumfield, W.C., 1995. Lost Russia. Duke University press, Durham.

Brumfield W.C., 2008. The Architectural Heritage of Solikamsk and the Northern Districts of Perm Province. «Cahiers slaves», n. 10, Routes et chemins slaves, pp. 317-355.

Brumfield, W.C., 2011. Usolye: Stroganov outpost in the Urals. Russia and India Report. Open Source http://in.rbth.com/articles/2011/08/11/usolye_stroganov_outpos t_in_the_urals_12850.html (1 July 2019)

Byrne, D. R., 2008. Heritage as social action. In: Fairclough, G. J., Harrison, R., Jameson, J. H., Schofield, J. The Heritage Reader. Routledge, London, pp. 149-173.

Feilden, B. M.; Jokilehto, J., 1998. Management Guidelines for World Cultural Heritage Sites. ICCROM, Rome.

Jokilehto, J., 1998. International trends in historic preservation: from ancient monuments to living cultures. APT Bulletin, 29 (34), pp. 17-19.

Kioussi, A., Labropoulos, K., Karoglou, M., Moropoulou, A., Zarnic, R., 2011. Recommendations and strategies for the establishment of a guideline for monument documentation harmonized with existing European standards and codes. Journal Geoinformatics FCE CTU, 6 (2011), pp. 178-184.

Kioussi, A., Karoglou, M., Labropoulos, K., Bakolas, A., Moropoulou, A., 2013. Integrated documentation protocols enabling decision making in cultural heritage protection. Journal of Cultural Heritage, 14 (3), pp. 141-146.

Langfield, M., Logan, W.S., Nic Craith, M., 2010. Cultural diversity, heritage and human rights: intersections in theory and practice. Routledge, London.

Logan, W. S., 2001. Globalizing heritage: world heritage as a manifestation of modernism and the challenge from the periphery. In: ICOMOS National Conference, Adelaide, Australia, pp. 51-57.

Logan W., 2012. Cultural diversity, cultural heritage and human rights: towards heritage management as human rights-based cultural practice. International Journal of Heritage Studies, 18 (3), pp. 231-244.

Mumford, L. 1963. The City in History, Edizioni di Comunità, Roma.
Osello, A., Ugliotti, F.M., 2017. BIM: verso il catasto del futuro. Conoscere, digitalizzare, condividere. Il caso studio della Città di Torino. Gangemi Editore, Roma.

Parrinello, S., Cioli, F., 2018. Un progetto di recupero per il complesso monumentale di Usolye nella regione della Kama Superiore. Restauro Archeologico, 1 (2018), pp. 92-111.

Parrinello, S., Dell'Amico, A., 2019. Experience of Documentation for the Accessibility of Widespread Cultural Heritage, 2 (2019, pp. 1032-1044.

Parrinello, S., Picchio, F., 2014. Recomposing the landscape using structure from motion survey in the village of Korza, Karelia (Russia). SCIRES-it, 4(2), pp. 29-42.

Pavan, A., Mirarchi, C., Giani, M., 2017. BIM: Metodi e strumenti. Progettare, costruire e gestire nell'era digitale, Tecniche nuove: Milano. 